ÁCIDOS E BASES: DESENVOLVIMENTO DE UMA SEQUÊNCIA DIDÁTICA PARA O ENSINO DE QUÍMICA

\title{
ACIDS AND BASES: DEVELOPMENT OF A SEQUENCE TEACHING FOR CHEMICAL TEACHING
}

\author{
DA COSTA, Maria Aparecida ${ }^{1 *}$ \\ ${ }_{1}^{1}$ Bolsista no Programa Institucional de Bolsa de Iniciação a Docência - PIBID/CAPES e Discente do Curso de \\ Licenciatura em Química no Instituto Federal de Educação, Ciência e Tecnologia de Goiás, Câmpus Itumbiara, \\ Av Furnas, 55, cep 75524-010, Itumbiara - GO, Brasil
}

(fone: +5564 21035600)

${ }^{*}$ Autor correspondente

e-mail: expedito191@hotmail.com

Received 1 March 2015; received in revised form 22 July 2015; accepted 24 Augustr 2015

\section{RESUMO}

É muito importante que os conteúdos químicos estejam relacionados com o cotidiano do aluno de modo que favoreça a compreensão do contexto social em que eles estão inseridos. Para que isso ocorra o professor pode se apropriar da elaboração de sequências didáticas para auxiliá-lo na escolha dos melhores recursos didáticos-pedagógicos a serem trabalhados em sala de aula, como jogos, experimentos e atividades que favoreçam a contextualização dos conteúdos. Ao buscar trabalhar dessa maneira os conteúdos, a partir da elaboração de sequências didáticas, essas contribuirão para despertar a curiosidade, motivação e participação dos alunos durante as aulas e favorecendo o processo ensino e aprendizagem. Nessa perspectiva o presente artigo teve como foco a elaboração de uma sequência didática para o conteúdo químico ácido e base, em que a partir dessa o professor pode trabalhar em sala de aula diversos recursos didáticos para o conteúdo aqui proposto. No entanto foram elaborados métodos diferenciados para ministrar o conteúdo químico ácido e base, utilizando assim, a experimentação, a confecção de um jogo e uma abordagem contextualizada. A escolha da metodologia aqui apresentada se deu com o intuito de que, a partir de sua utilização esta possa favorecer um melhor aproveitamento do conteúdo por parte dos alunos e que eles possam compreender melhor o conteúdo e a relação da química com o seu contexto social.

Palavras-chave: Experimentação, Jogos, Contextualização.

\begin{abstract}
It is very important that the chemical contents are related to the daily life of the student in order to favor the understanding of the social context in which they are inserted. For this to occur the teacher can appropriate the elaboration of didactic sequences to assist you in choosing the best teaching-learning resources to be worked in the classroom, such as games, experiments and activities that favor the contextualization of the contents. In seeking work in this way the contents, from the elaboration of didactic sequences, these will contribute to arouse curiosity, motivation and participation of students in class and encouraging the teaching and learning process. From this perspective the present article focused on the development of a didactic sequence for the chemical content acid, where from that the teacher can work in the classroom various teaching resources for the content herein. However they were developed different methods to teach the chemical content acid and base, using so experimentation, making a game and a contextualized approach. The choice of the methodology presented here it was with the intention that, from this use can encourage a better use of the content by the students and that they can better understand the content and the relationship of chemistry with your social context.
\end{abstract}

Keywords: Experimentation, Games, Contextualization. 


\section{INTRODUÇÃO}

A forma como os conteúdos são ministrados em sala de aula, é um dos motivos que podem influenciar para a motivação ou desmotivação dos alunos, pois a quantidade excessiva de conteúdos, muitas vezes abstratos ou ensinados de maneira confusa, colabora com os fatores que desmotivam o estudo da química (CARDOSO e COLINVAUX, 2000).

Ao pensarmos no ensino de química, é importante refletirmos em torno de como tem sido trabalhada a química em sala de aula, quais os recursos pedagógicos que o professor tem buscado inserir para tentar despertar no aluno o interesse pela química e relacioná-la com o contexto social do aluno, para que assim favoreça o processo de ensino e aprendizagem.

Atualmente, ao analisarmos diversos trabalhos realizados na área do ensino de química, nota-se que muitas vezes os alunos apresentam grande dificuldade na disciplina de química. Essa disciplina, quando trabalhada de forma de tradicional, sem o apoio de recursos pedagógicos para ministrar os conteúdos, acaba contribuindo para essa dificuldade apresentada pelos alunos.

Sendo assim, Soares et al., (2003), propõem 0 desenvolvimento de estratégias modernas e simples, utilizando experimentos, atividades lúdicas ou jogos e recursos didáticos que contribuam para a dinamização no ensino de química. Diante dessa afirmação, é necessário que o professor esteja sempre disposto a buscar meios alternativos para dinamizar suas aulas, contribuindo assim para que os alunos tenham uma melhor compreensão dos conteúdos estudados.

Nessa perspectiva, um dos meios alternativos em que o professor pode recorrer para tornar sua aula mais atraente e motivar os alunos para o conteúdo proposto é o jogo, que pode ser criado pelo próprio professor ou até mesmo utilizar jogos que já foram desenvolvidos.

Os jogos são indicados como um tipo de recurso didático que pode ser utilizado em momentos distintos, como na apresentação de um novo conteúdo, ilustração de aspectos relevantes ao conteúdo, revisão ou síntese de conceitos importantes e avaliação de conteúdos já desenvolvidos (CUNHA, 2004).

Segundo Miranda (2001), mediante a utilização do jogo didático, vários objetivos pode ser atingidos, relacionados à cognição (desenvolvimento da inteligência e da personalidade, fundamentais para a construção de conhecimentos); afeição (desenvolvimento da sensibilidade e da estima e atuação no sentido de estreitar laços de amizade e afetividade); socialização (simulação de vida em grupo); motivação (envolvimento da ação, do desfio e mobilização da curiosidade) e criatividade.

Outra forma de promover uma melhor compreensão dos conteúdos por parte dos alunos e atrair a atenção para os temas que estão sendo estudados é utilizando a experimentação, pois esta permite ao aluno relacionar a teoria à prática. Nesse sentido, no ensino de química a experimentação pode ser uma estratégia eficiente para a criação de problemas reais e que permitam a contextualização dos conteúdos e o estímulo de questionamentos para a investigação.

A experimentação tende a despertar nos alunos, um forte interesse pelos conteúdos devido seu caráter motivador, lúdico, essencialmente vinculado aos sentidos, pois os alunos são envolvidos através de aspectos visuais como cores, texturas e odores o que faz estreitar o elo entre a motivação e a aprendizagem (BENITE et al., 2009).

Espera-se então que o envolvimento dos alunos seja maior e leve a evoluções em termos conceituais. Segundo Machado et al, (1999), professores que partiram das reflexões feitas sobre suas vivências em sala de aula, concluíram que a experimentação é uma ferramenta que pode ter grande contribuição na explicitação, problematização e discussão dos conceitos com os alunos, criando condições favoráveis à interação e intervenção pedagógica do professor.

Para Abraham et al., (1997), o ensino de química centrado nos conceitos científicos, sem incluir situações reais, torna-se pouco motivador para o aluno. A atividade experimental no ensino da química é uma importante ferramenta pedagógica, apropriada para despertar o interesse dos alunos, cativá-los para os temas propostos pelos professores e ampliar a capacidade para o aprendizado.

Além da experimentação e do desenvolvimento de jogos/atividades lúdicas é muito impor-

PERIÓDICO TCHÊ QUÍMICA • www.periodico.tchequimica.com • Vol. 12 N. 24. - ISSN 1806-0374 (impresso) • ISSN 1806-9827 (CD-ROM) • ISSN 2179-0302 (meio eletrônico) 
tante que o professor trabalhe os conteúdos de forma contextualizada, relacionando com o cotidiano do aluno de modo que ele reflita sobre a influência do conceito químico com o contexto social em que ele está inserido e não somente sua exemplificação.

A aprendizagem por meio da contextualização envolve o estudo de conceitos químicos presentes no cotidiano, permitindo ao aluno construir e reconstruir conhecimentos que os ajudarão a terem uma leitura crítica do mundo físico, possibilitando tomar decisões fundamentadas em conhecimentos científicos, promovendo o exercício da cidadania (BRASIL, 1999).

Zabala (1998), argumenta que o ensino de química deve possibilitar ao aluno o seu envolvimento numa visão crítica do mundo que o cerca, podendo ainda analisar, compreender e utilizar este conhecimento para reconhecer a química como parte integrante de nossas vidas, sendo, assim, a melhor maneira de atrair a atenção dos alunos.

Os PCNEM (BRASIL, 1999) propõem que a contextualização dos conteúdos a serem apreendidos é um importante recurso para "retirar o aluno da condição de espectador passivo" e para "tornar a aprendizagem significativa ao associá-la com experiências da vida cotidiana ou com os conhecimentos adquiridos espontaneamente".

Montenegro (2008) argumenta que "na escola brasileira, o ensino de ciências tem sido tradicionalmente livresco e descontextualizado, levando o aluno a decorar, sem compreender os conceitos e a aplicabilidade do que se é estudado".

Sendo assim, é necessário que a contextualização esteja centrada na abordagem de temas sociais, onde são trabalhadas a integração de conceitos científicos e a discussão dos aspectos sociais, para que o aluno entenda o contexto em que está inserido, e sendo assim, exigindo deste um posicionamento crítico quanto sua solução.

Ao se trabalhar de forma contextualizada determinado conteúdo químico, o professor torna possível uma melhor reflexão do aluno para com o contexto social em que ele está inserido. Acredita-se, assim como Kishimoto (1996), que o professor deve rever a utilização de propostas peda- gógicas passando a adotar em sua prática aquelas que atuem nos componentes internos da aprendizagem, já que estes não podem ser ignorados quando o objetivo é a apropriação de conhecimentos por parte do aluno.

Nesse sentido o presente artigo teve como proposta, a elaboração de uma sequência didática para o conteúdo químico ácido e base, utilizando diversos recursos didáticos, desde seu conceito histórico até sua aplicação no cotidiano, trabalhando com experimento para que o aluno possa compreender a teoria na prática e também de forma contextualizada indicando sua relação com o meio social.

Nesse contexto a sequência didática contribui para que o professor reflita em simplesmente deixar de transmitir conhecimento para assumir o papel de criador de situações estimulantes, para si próprio e seus alunos (LEAL, 2013).

De acordo com Zabala (1998), a motivação para a aprendizagem não provém da sequência didática em sí, mas do modo como ela está sendo trabalhada. A maneira de apresentá-la e o tipo de atividade estabelecida pelo professor e o aluno, os exemplos utilizados, o grau de identificação dos conteúdos são maneiras que o professor pode utilizar para despertar a motivação pela aprendizagem no aluno.

Portanto, espera-se que o professor ao se apropriar de tais recursos possa desenvolver sua aula de forma a atrair e estimular o aluno para o conteúdo químico proposto, gerando assim uma maior participação e uma aprendizagem mais significativa e ao mesmo tempo promover aos alunos uma melhor leitura do mundo e do contexto social em que estão inseridos.

\section{DESENVOLVIMENTO}

Para a elaboração da sequência didática aqui proposta, foram realizados diversos estudos através de pesquisas bibliográficas, tendo como base uma consulta de fontes secundárias relativas ao conteúdo químico ácido e base escolhido, tais como livros didáticos, artigos científicos e monografias.

A proposta da sequência didática descrita é que ela seja utilizada em turmas de $2^{\circ}$ ano do ensino médio, em escolas públicas da rede estadual do município de Itumbiara-GO e até 
mesmo em outras instituições de ensino de outras cidades. Para se tornar produtiva a aplicação dos conteúdos serão utilizados diversos recursos didáticos, tais como, texto, experimentos e jogos/atividades lúdicas. Para seguir corretamente sua abordagem didática, foi utilizado o livro de química do segundo ano do ensino médio, Ricardo Feltre Volume. 2, em que traz a sequência dos temas abordado a partir do conteúdo ácido e base.

Após a aplicação dessa sequência didática será aplicado aos alunos um questionário, que buscará diagnosticar se as atividades realizadas contribuíram para uma melhor compreensão do conteúdo ministrado. Para elucidar melhor essa proposta foi criado o Cronograma 1 para discutir a respeito das atividades a serem desenvolvidas antes de sua aplicação, para determinar sua viabilidade.

Cronograma 1: Roteiro para elaboração das sequências didática.

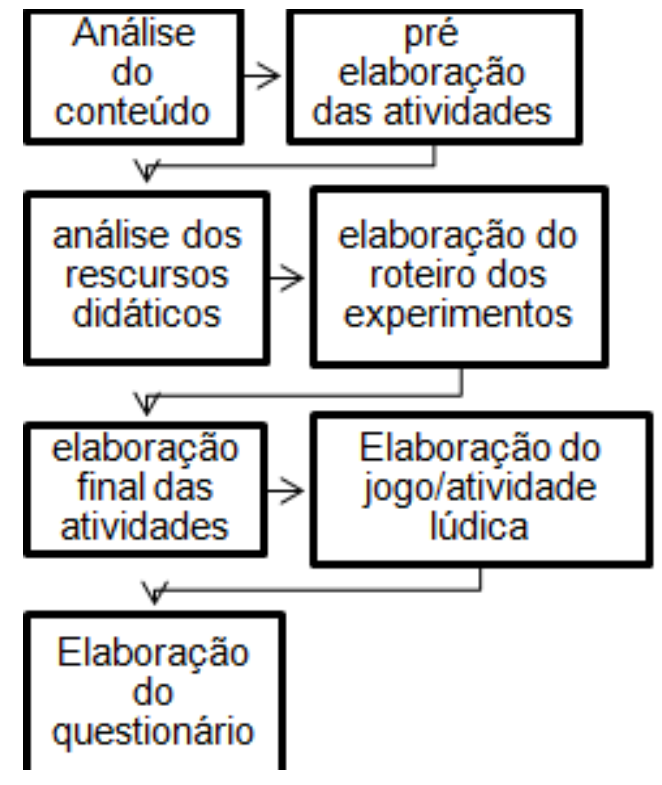

O cronograma criado serviu como suporte para organização das etapas da sequência didática, procurando a forma adequada de relacionar as atividades com os conteúdos e os recursos necessários. Ressalta-se ainda que a sequência didática elaborada levará em torno de quatro aulas de 50 minutos para sua realização.

\section{RESULTADOS E DISCUSSÃO}

Os tópicos que serão utilizados para o conteúdo químico ácido e base tem a sequência elucidado no Quadro 1 de acordo com o livro didático Ricardo Feltre Volume 2, de química do ensino médio do segundo ano.

Quadro 1. Descrição do conteúdo químico ácido e base.

\begin{tabular}{|l|}
\hline \multicolumn{1}{|c|}{ Questões abordadas } \\
\hline Conceito ácido e base \\
\hline Acidez e $\mathrm{pH}$ \\
\hline Ação dos ácidos e das bases \\
\hline A teoria de Arrhenius \\
\hline A teoria de Bronsted-Lowry \\
\hline A teoria de Lewis \\
\hline Nomenclatura \\
\hline
\end{tabular}

Fonte livro de Química Ricardo Feltre, Volume 2.

Para tanto, cada tópico que será trabalhado em cada aula foi desenvolvido uma abordagem com metodologias diferenciadas entre si. O Quadro 2 demonstra como será trabalhado cada conteúdo nessa sequência didática de tema por aula e os recursos didáticos que serão utilizados.

Quadro 2. Metodologia prevista para cada tema.

\begin{tabular}{|c|c|}
\hline Tema/Aula & Recursos \\
\hline $\begin{array}{l}\text { Conceito ácido e base, } \\
\text { A teoria de Arrhenius, } \\
\text { Bronsted-Lowry } \\
\text { Lewis }\end{array}$ & $\begin{array}{l}\text { Aula expositiva com } \\
\text { recursos } \\
\text { audiovisuais. }\end{array}$ \\
\hline $\begin{array}{l}\text { Acidez, basicidade e } \\
\mathrm{pH}\end{array}$ & $\begin{array}{l}\text { Realização } \\
\text { experimento } \\
\text { simples }\end{array}$ \\
\hline $\begin{array}{l}\text { Ação dos ácidos e das } \\
\text { bases }\end{array}$ & $\begin{array}{l}\text { Realização } \\
\text { experimentos }\end{array}$ \\
\hline $\begin{array}{l}\text { Nomenclatura } \\
\text { ácido e base }\end{array}$ & $\begin{array}{l}\text { Utilização } \\
\text { jogo/atividade } \\
\text { lúdica. }\end{array}$ \\
\hline Chuva ácida & $\begin{array}{l}\text { Estudo de Texto e } \\
\text { experimento }\end{array}$ \\
\hline
\end{tabular}

Autora

Como foram apresentados no Quadro 2 os recursos didáticos a serem utilizados, nota-se a utilização dos experimentos e atividades envolvendo jogos/atividades lúdicas, o que contribui para atrair os alunos de maneira efetiva, gerando assim sua participação e interação na 
realização das atividades, promovendo também a interação entre professor-aluno e aluno-aluno, o que contribui para uma melhor compreensão do conteúdo. A seguir descreve-se como proceder em cada a aula com a sequência didática elaborada.

\subsection{Aula I - Aula teórica expositiva}

Na primeira aula, o professor poderá introduzir na sala de aula o marco histórico a respeito dos ácidos e das bases, de como ocorreu sua descoberta e quais químicos contribuíram para tal. Poderá ser abordado ainda a respeito da origem da palavra ácido e base, apresentar a escala de $\mathrm{pH}$ aos alunos e explicar como funciona, explicando sobre os indicadores ácidos e bases.

A partir disso o professor pode trabalhar as definições de ácido e base propostas por Arrhenius, Bronsted Lowry e Lewis descritas no Quadro 3.

Quadro 3. Definição para ácido e base.

\begin{tabular}{|c|c|c|}
\hline Teoria & Ácido & Base \\
\hline Arrhenius & $\begin{array}{l}\text { Ácido é toda } \\
\text { substância que } \\
\text { em água libera } \\
\text { íons } \mathrm{H}^{+}\end{array}$ & $\begin{array}{l}\text { Base é toda } \\
\text { substância que } \\
\text { em água libera } \\
\text { íons } \mathrm{OH}^{-}\end{array}$ \\
\hline $\begin{array}{l}\text { Bronsted- } \\
\text { Lowry }\end{array}$ & $\begin{array}{l}\text { Ácido é toda } \\
\text { substância que } \\
\text { pode doar } \\
\text { prótons }\end{array}$ & $\begin{array}{l}\text { Base é toda } \\
\text { substância que } \\
\text { pode receber } \\
\text { prótons }\end{array}$ \\
\hline Lewis & $\begin{array}{l}\text { Ácidas são } \\
\text { espécies } \\
\text { capazes de } \\
\text { receber pares } \\
\text { de elétrons }\end{array}$ & $\begin{array}{l}\text { Bases são } \\
\text { espécies } \\
\text { capazes de } \\
\text { receber doar de } \\
\text { elétrons }\end{array}$ \\
\hline
\end{tabular}

Fonte. Livro de Química. V. 2. Ricardo Feltre

Diante dessas definições o professor pode dar continuidade ao conteúdo explicando sobre as teorias, diferenciando-as e falando aos alunos qual teoria é aceita hoje no mundo da química, sendo a teoria mais abrangente a de Lewis.

\subsection{Aula II - Experimentos}

$\mathrm{Na}$ segunda aula, em que o professor trabalhará com os experimentos, deve-se proceder da seguinte maneira. Durante a realização do experimento previsto, os alunos podem confeccionar seu próprio indicador ácido e base a partir do repolho roxo. O roteiro de como proceder para fabricar o indicador ácido e base a partir do repolho roxo, bem como os materiais que são utilizados e os procedimentos a serem seguidos está descrito no Quadro 4.

Quadro 4. Indicador com repolho roxo.

\begin{tabular}{|l|}
\hline \multicolumn{1}{|c|}{ Materiais } \\
\hline Folhas de repolho roxo \\
Recipiente para aquecimento \\
Fonte de calor \\
Filtro de papel \\
Frasco com conta gotas \\
\hline \multicolumn{1}{|c|}{ Procedimentos } \\
\hline Pegue cinco folhas de repolho roxo e corte- \\
as em pedaços pequenos \\
Coloque os pedaços de repolho roxo em um \\
recipiente que possa ir ao aquecimento e \\
acrescente água destilada até o dobro do \\
volume ocupado pelo repolho \\
Aqueça a água com o repolho roxo até que \\
seu volume reduzir a metade do volume \\
inicial \\
Deixe esfriar e coe com o papel filtro \\
Coloque o extrato do repolho roxo obtido em \\
um frasco de conta gostas, rotule e coloque- \\
o na geladeira \\
\hline
\end{tabular}

Fonte. Livro de Química. V. 2. Ricardo Feltre.

A realização desse experimento permite que o aluno tenha um contato direto com a aplicação do conteúdo de forma a aplicar a teoria na prática e perceber a ação do indicador na mudança de cor das soluções, identificando por meio delas o ácido e a base, podendo ainda aprender sobre os indicadores naturais.

As soluções que podem ser utilizadas para testar o efeito do indicador feito a partir do repolho roxo e que são de fácil aquisição são: Vinagre, Limão, Laranja, $\mathrm{NaOH}$, Shampoo, Óxido de Cálcio e Álcool, podendo ainda ser utilizadas pelo professor outras soluções.

Após o teste do experimento o professor pode propor ainda questões aos alunos como ocorre a variação do $\mathrm{pH}$ a partir da cor final das soluções ao adicionar o extrato de repolho roxo, que no caso será utilizado como indicador ácidobase no lugar da fenolftaleína.

A partir das cores observadas em cada teste realizado nas soluções após a adição do suco do repolho roxo, os alunos podem 
identificar quem é o ácido e a base pela tonalidade da cor com a ajuda de uma escala de $\mathrm{pH}$ como a elucidada na Figura 1.

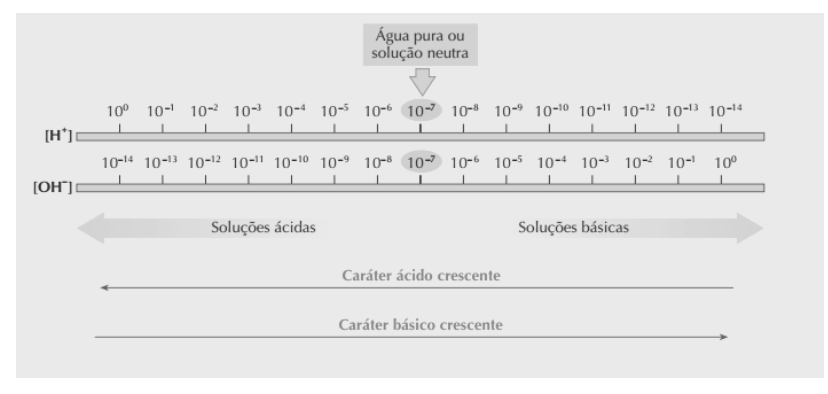

Figura 1. Escala de $\mathrm{pH}$.

Fonte livro de Química Ricardo Feltre, Volume 2.

Com o auxílio da escala de $\mathrm{pH}$ os alunos podem compreender o processo de variação da cor nas soluções utilizadas, confirmando quais será ácida ou básica.

O roteiro do experimento para simulação de uns dos efeitos decorrentes da chuva ácida (Quadro 5), será trabalhado ao final do estudo do conteúdo proposto, para que alunos possam relacionar a teoria à prática e ao contexto da chuva ácida no meio social.

Como esse experimento deve ser realizado preferencialmente na última aula, para conclusão das atividades propostas na sequência didática, ressalta-se então que este experimento tem duração de 30 minutos para observar o efeito. Sendo assim, o professor pode iniciar a aula com a preparação do experimento e enquanto aguarda o tempo definido ele trabalha a parte teórica relacionada à chuva ácida.

Quadro 5. Simulação do efeito da chuva ácida.

\begin{tabular}{|l|}
\hline \multicolumn{1}{|c|}{ Materiais } \\
\hline Colher \\
20 gramas de enxofre \\
Duas flores \\
Recipiente com tampa \\
Arame \\
Prego \\
Vela \\
Fita isolante \\
Isqueiro \\
Papel indicador de pH \\
\hline \multicolumn{2}{|c|}{ Procedimentos } \\
\hline Prenda o papel indicador dentro do recipiente \\
com a fita isolante \\
Com auxílio do prego perfure a tampa do \\
recipiente em dois lugares \\
Dobre a extremidade da colher para que ela \\
\hline
\end{tabular}

forme um gancho

Com o arame, passe-o pelos furos para que ele segure a colher

Coloque 20 gramas do enxofre na colher

Coloque uma flor dentro do recipiente

Com auxílio do isqueiro acenda a vela e coloque-a em baixo da tampa do recipiente com colher já com as 20 gramas de enxofre até que comece soltar uma fumaça

Em seguida tampe o recipiente e aguarde 30 minutos para observar o que acontece com a flor lá dentro

$$
\text { Fonte: IQUSP (1993). }
$$

No entanto, o objetivo do experimento é conscientizar o aluno sobre a emissão de gases poluentes para a atmosfera e consequentemente resultando na chuva ácida. Ocorrerá então a demonstração da contribuição do $\mathrm{SO}_{2}$ (óxido de enxofre) para o aumento da acidez na chuva e discutir sobre o processo da formação dessa chuva, apresentando os malefícios da emissão de $\mathrm{SO}_{2}$, os prejuízos que a chuva ácida causa, e como cada um pode contribuir para minimizar esse problema.

Em razão do enxofre (S) ser aquecido entrando em contato com o oxigênio presente do ar presente dentro do recipiente, ocorre à formação de uma névoa densa dentro do recipiente, contribuindo para a mudança na coloração da rosa, indicando que houve a produção de ácido sulfúrico $\left(\mathrm{H}_{2} \mathrm{SO}_{4}\right)$ dentro do recipiente (Quadro 6).

Quadro 6. Processo de formação de ácido sulfúrico no experimento.

\begin{tabular}{|c|c|c|}
\hline \multicolumn{3}{|c|}{ Reação química no processo } \\
\hline $\begin{array}{l}\mathrm{S}+\mathrm{O}_{2} \rightarrow \mathrm{SO}_{2} \\
\text { (S) e formação de } \mathrm{SC}\end{array}$ & $\begin{array}{l}\text { Queir } \\
\text { D }_{2} \text { (óxidc }\end{array}$ & $\begin{array}{l}\text { le enxofre } \\
\text { enxofre). }\end{array}$ \\
\hline $\begin{array}{l}\mathrm{SO}_{2}+1 / 2 \mathrm{O}_{2} \rightarrow \mathrm{SO}_{3} \\
\mathrm{SO}_{3}+\mathrm{H}_{2} \mathrm{O} \rightarrow \mathrm{H}_{2} \mathrm{SO}_{4} \\
\text { Produção }\end{array}$ & ácido & sulfúrico. \\
\hline
\end{tabular}

Fonte: IQUSP (1993).

O papel indicador ácido e base muda de cor ao entrar em contato com $\mathrm{H}_{2} \mathrm{SO}_{4}$ (ácido sulfúrico) formado pela queima do enxofre (S). O processo acima é uma demonstração do que 
ocorre na natureza. A chuva rica em ácidos, como $\mathrm{H}_{2} \mathrm{SO}_{4}$, tem o poder de corroer tudo que ela toca, desde substâncias mais duras (mármore e metais) até frágeis plantas.

A simulação da chuva ácida é um experimento ligado à realidade do aluno. Possibilitando que ele reconheça e compreenda de forma significativa às transformações químicas que ocorrem no processo natural da atmosfera. Deve-se então, considerar também o envolvimento ativo do aluno no processo de investigação e na produtividade do experimento bem como reflexão na solução de problemas relacionados ao ambiente no qual está inserido.

A proposta do experimento apresentada e e. tornar o ensino mais relevante, permitindo ao aluno o pensamento conceitual, compreensão de forma integrada e significativa das transformações químicas que ocorrem nos processos naturais em diferentes contextos (LIMA et al., 2007).

\subsection{Aula III - Jogo/atividade lúdica}

Para a terceira aula, foi elaborado um jogo referente ao conteúdo ácido e base. A Figura 2 ilustra o jogo confeccionado para a fixação dos ácidos e das bases mais comuns utilizados no cotidiano. O jogo possuí um total de 24 cartas, funcionando como se fosse um jogo de memória, em que o aluno tem uma carta com o nome do ácido ou base e deve procurar a carta que contenha a especificação de sua utilização.

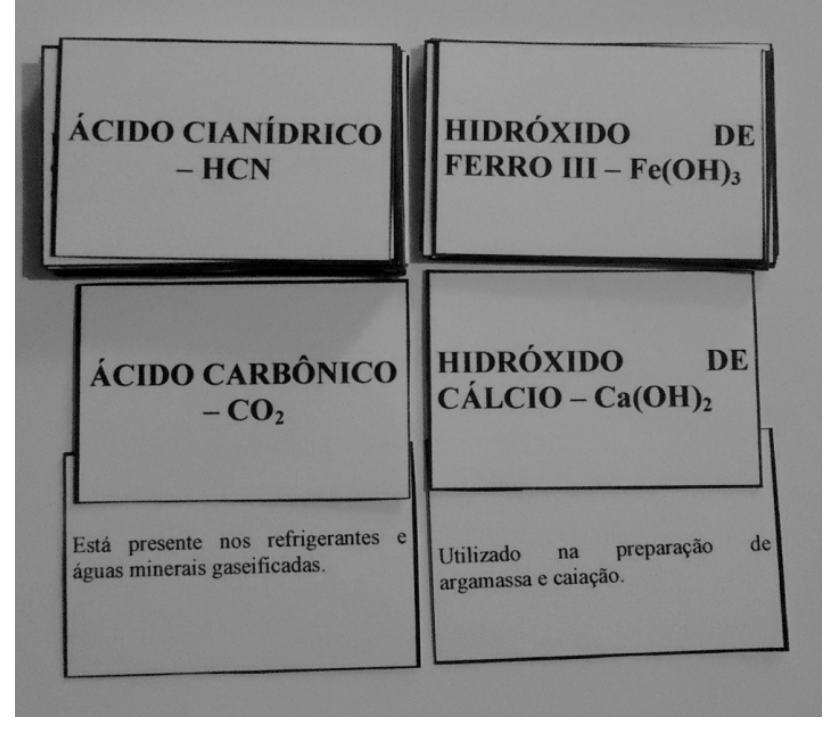

Figura 2. Algumas cartas do jogo. Autora.
As regras para realização do jogo são da seguinte forma:

1. O aluno já deve ter estudado o conteúdo ácido e base, bem como sua aplicação,

2. A sala deve ser dividida em quatro grupos,

3. Cada grupo ficará com um exemplar do jogo (o mesmo foi confeccionado com material de baixo custo, podendo assim ter mais exemplares),

4. As cartas com o nome do ácido/base devem ficar viradas para baixo,

5. Cada aluno pegará uma carta do monte e verificará o nome do seu ácido/base,

6. Em seguida os alunos procuram pela carta que tenha função do seu ácido/base,

Ao terminar a rodada os alunos deverão escolher outra carta e repetir todo o procedimento, ao acabarem as cartas devolvam-nas ao monte embaralhadas para que se inicie uma nova rodada.

Durante a realização do jogo é necessário que o professor esteja atento aos grupos dando orientações em caso de possíveis dúvidas. Como forma de premiar o aluno vencedor de cada grupo, o professor pode optar por caixinhas de bis e pedir para que o aluno vencedor distribua aos outros colegas de seu grupo.

Sendo assim, Piaget (1978), afirma que os jogos/atividades lúdicas não são apenas uma forma de entretenimento para gastar a energia os alunos, mas meios que enriquecem o desenvolvimento intelectual e que podem contribuir significativamente para o processo de ensino aprendizagem e no processo de socialização dos indivíduos.

Além de o jogo promover a fixação do nome e função dos ácidos e das bases, ele proporciona também um momento de interação entre os alunos e o professor. A partir do jogo dessas cartas para fixar a ação dos ácidos e bases e sua utilização, o professor pode trabalhar a nomenclatura.

\subsection{Aula IV - Chuva Ácida}

Na quarta aula, para melhor contextualizar o conteúdo químico trabalho, o professor pode se apropriar de textos ou noticiários que relatam problemas ocasionados pela chuva ácida, para que os alunos possam compreender a influência da chuva ácida no contexto social e suas implica- 
ções ao meio ambiente a partir do conteúdo químico ácido e base estudado.

Além dos textos e noticiários relacionados à temática chuva ácida, o professor pode ainda trazer para a aula figuras referentes aos problemas provocados pela chuva ácida, e o próprio ciclo da chuva ácida para um momento de discussão com os alunos, para que eles possam compreender como ocorre o processo que torna a chuva ácida. O processo de formação da chuva ácida está elucidada na Figura 3.

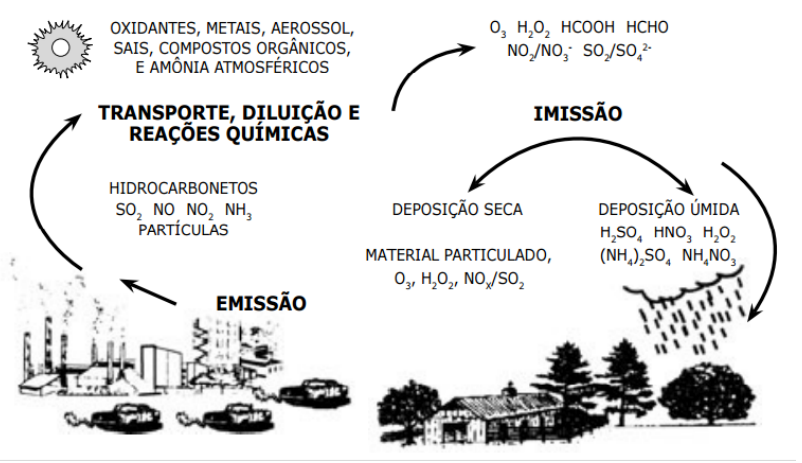

Figura 3. Ciclo da chuva ácida Fonte: Fornaro (1991).

A Figura 3 melhor ilustra o processo de formação da chuva ácida, pela liberação dos gases das indústrias e carros, os alunos podem compreender melhor sobre esse processo, como se da liberação dos gases para a atmosfera e sua relação com a chuva para torná-la ácida.

Após a abordagem do processo e as causas da formação da chuva ácida, é muito importante que o professor trabalhe com os alunos as causas ao meio ambiente provocado pela mesma.

Nessa perspectiva, Mello (2004) argumenta que o ensino de Química possibilita ao aluno a compreensão dos processos químicos no sentido de construir o conhecimento científico, facilitando o entendimento quanto à sua aplicação na sociedade, permitindo-lhe construir uma nova interpretação do mundo, estando consciente de seu poder em transformar a sua realidade.

No entanto, um dos grandes danos provocados pela chuva ácida é a destruição de obras civis e monumentos. Nesses últimos anos, os principais monumentos históricos sofreram severas agressões provocadas pelo ácido. Nessa perspectiva o professor pode ainda gerar um momento de debate entre os alunos para promover discussões em torno de como reduzir os efeitos causados pela chuva ácida e até mesmo possíveis soluções para diminuir a acidez da mesma. Podem ser apresentadas aos alunos ao final do debate algumas propostas para reduzir essa formação da chuva ácida, como:

- Incentivar a utilização de transportes coletivos, como forma de diminuir o número de veículos a circular nas estradas.

- Utilizar metros em substituição dos carros a diesel, ou então promover a sua substituição por frotas não poluentes.

- Incentivar a descentralização industrial.

- Remoção de poluentes dos combustíveis com alto teor de enxofre antes da sua distribuição a consumo.

- Remoção de poluentes dos gases de combustão nas indústrias antes do seu lançamento na atmosfera.

- Subsidiar a utilização de combustíveis limpos (gás natural, energia elétrica de origem hidráulica, energia solar e energia eólica) em fontes de poluição tipicamente urbana como hospitais, lavanderias e restaurantes.

- Utilizar combustíveis limpos em veículos, indústrias e caldeiras.

Ao realizar essa discussão, de propor soluções para os problemas ambientais ocasionados pela chuva ácida, o professor promove um ensino de química a partir do conteúdo ácido e base contextualizado e dinâmico. A sequência didática aqui proposta serve como apoio para ministrar o conteúdo, deixando livre que o professor possa inserir outras metodologias.

Sendo assim, a aprendizagem por meio da contextualização envolve a vinculação de temas sociais e situações reais aos conteúdos, possibilitando a discussão transversal dos conteúdos com os conceitos científicos, permitindo assim aos alunos a compreensão do contexto social em que estão inseridos desenvolvendo a capacidade da tomada de decisões (SANTOS, 2007).

Ao final de todo o processo da aplicação desta sequência didática, se o professor preferir, ele pode realizar um diagnóstico a partir da aplicação de um questionário para extrair os 
possíveis pontos negativos e positivos da abordagem das aulas. O Quadro 7 trás descrito a proposta de aplicação do questionário.

Quadro 7. Questionário para aplicar após a aula.

\begin{tabular}{|l|c|}
\hline \multicolumn{4}{|c|}{ Questões } \\
\hline i. & O jogo auxiliou na compreensão do \\
conteúdo aplicado? & Aprende-se melhor o conteúdo \\
\hline ii. & quando utiliza experimentos e jogos? \\
\hline iii. & O jogo contribuiu para seu \\
& $\begin{array}{l}\text { relacionamento com os colegas, visto } \\
\text { que este foi trabalhado em grupo? }\end{array}$ \\
\hline iv. A maneira como as aulas foram \\
desenvolvidas despertou seu interesse \\
pelo conteúdo? \\
v. Você teve alguma dificuldade na \\
realização das atividades?
\end{tabular}

Autora

\section{CONCLUSÕES}

Visando a proposta do planejamento de uma sequência didática para o conteúdo químico ácido e base, espera-se que a metodologia adotada tenha efeito positivo em sua aplicação, e que possa favorecer de maneira significativa 0 processo de ensino e aprendizagem.

Nota-se que na realização das atividades, envolvendo jogos, experimentos e situações relacionadas ao cotidiano dos alunos, estas contribuem para interação entre professor e os alunos, a compreensão do contexto social em que estão inseridos, e ao mesmo tempo relacionando a teoria e prática.

Diante do exposto é possível inferir que as propostas didáticas podem auxiliar o professor no momento da escolha dos recursos didáticos, que favorecerão no processo ensino-aprendizagem dos alunos, utilizando-se da contextualização para abordar conceitos químicos de grande relevância no contexto social.

Ressalta-se ainda que, é de suma importância que o professor busque métodos diferenciados e atrativos para se trabalhar com conteúdos químicos, pois dessa forma o professor contribui para uma melhor qualidade no ensino de química.

\section{REFERÊNCIAS}

1. ABRAHAM, M. R.; CRAOLICE, M. S.;
GRAVES, A. P.; ALDHAMASH, A. H; KIEHGA, J. G.; GAL, J. G. P. The nature and state of general chemistry laboratory courses offered by colleges and universities in de United States. Journal of Chemical Education, v. 74, n. 5, p. 591-594, 1997.

2. BRASIL. Ministério da Educação. Secretaria de Educação Média e Tecnológica. Parâmetros curriculares nacionais: ensino médio. Brasília: MEC/SEMTEC, 1999. $4 \mathrm{v}$.

3. BENITE A. M. C.; BENITE, C. R. M. O laboratório didático no ensino de química: uma experiência no ensino público brasileiro. Revista Iberoamericana de Educación. n. ${ }^{\circ}$ 48/2, pp. 1-2, 2009.

4. CARDOSO, S. P e COLINVAUX, D. Explorando a Motivação para Estudar Química. Química Nova. Ijuí, UNIJUÍ, v.23, n.3. p. 401-404, 2000.

5. CUNHA, M. B. Jogos de Química: Desenvolvendo habilidades e socializando o grupo. Eneq 028- 2004.

6. FELTRE, Ricardo. Química 2 - FísicoQuímica. Vol. 3, $7^{\mathrm{a}}$ Ed. São Paulo: Moderna, 2008.

7. FORNARO, A. "Chuva Ácida em São Paulo: Caracterização Química de Amostras Integradas e Seqüenciais de Deposição Úmida". Dissertação de mestrado. São Paulo, Universidade de São Paulo, Instituto de Química, 1991.

8. GRUPO DE PESQUISA EM EDUCAÇÃO QUÍMICA. Interações e Transformações - Química para o 20 Grau - Livro do Aluno / GEPEQ. - IQUSP São Paulo, EDUSP,1993.

9. KISHIMOTO, T. M. Jogo, brinquedo, brincadeira e educação. Cortez, São Paulo, 1996.

10. LEAL, C. A. Vamos brincar de quê?: Os jogos cooperativos no ensino de ciências /Cristianni Antunes Leal; Orientadora Giselle Rôças. Nilópolis, RJ, 2013.166f.

11. LIMA, J. B.; MATOS, A. A. Chuva ácida: experimento de química ligado a poluição do ar. Disponível em: <http://www.abq.org.br/cbq/2007/trabalho s/6/6-236-463.htm>. Acesso em: $14 \mathrm{Fev}$. 2015.

12. MACHADO, A. H.; CASTILHO, D. L.; 
SILVEIRA, K. P. As aulas de Química como espaço de investigação e reflexão. Química Nova na Escola, №. 9, maio, 1999.

13. MELLO, M. R. Ensino de ciências uma participação ativa no cotidiano. Unijui, 2004.

14. MIRANDA, S. No Fascínio do jogo, a alegria de aprender. In: Ciência Hoje, v.28, 2001 p. 64-66.

15. MONTENEGRO, P.P, Letramento Científico: 0 despertar do conhecimento das Ciências desde os anos iniciais do Ensino Fundamental. Dissertação de Mestrado. Universidade de Brasília, julho de 2008.

16. PIAGET, J. A Formação do Símbolo na
Criança: imitação, jogo e sonho. Rio de Janeiro: Zanar, 1978.

17. ZABALA, A. A prática educativa como ensinar. Porto Alegre: Artmed, 1998.

18. SOARES, M. H. F. B Okumura, F.; Cavalheiro, E. T. G. Proposta de um jogo didático para ensino do conceito de equilíbrio químico. Química Nova na Escola, n. 18, p. 13-17, 2013.

19. SANTOS, W. L. P., Contextualização no Ensino de Ciências por meio de Temas CTS em uma perspectiva crítica. Ciência \& Ensino, v.1, n. especial, Nov. 2007. 